\title{
A Mutation in the DNA-binding Domain of the Androgen Receptor Gene Causes Complete Testicular Feminization in a Patient with Receptor-positive Androgen Resistance
}

\author{
M. Marcelli, S. Zoppi, P. B. Grino, J. E. Griffin, J. D. Wilson, and M. J. McPhaul \\ Department of Internal Medicine, University of Texas Southwestern Medical Center at Dallas, Dallas, Texas 75235-8857
}

\begin{abstract}
Androgen resistance is associated with a wide range of quantitative and qualitative defects in the androgen receptor. However, fibroblast cultures from $\sim 10 \%$ of patients with the clinical, endocrine, and genetic features characteristic of androgen resistance express normal quantities of apparently normal androgen receptor in cultured genital skin fibroblasts (receptorpositive androgen resistance). We have analyzed the androgen receptor gene of one patient (P321) with receptor-positive, complete testicular feminization and detected a single nucleotide substitution at nucleotide $2006(\mathrm{G} \rightarrow \mathrm{C})$ within the second "zinc finger" of the DNA-binding domain that results in the conversion of the arginine residue at position 615 into a proline residue. Introduction of this mutation into the androgen receptor CDNA and transfection of the expression plasmid into eukaryotic cells lead to the synthesis of a receptor protein that displays normal binding kinetics but is inactive in functional assays of receptor activity. We conclude that substitution mutations in the DNA-binding domain of the androgen receptor are one cause of "receptor-positive" androgen resistance. ( $J$. Clin. Invest. 1991. 87:1123-1126.) Key words: "zinc-finger" • steroid receptor $\bullet$ substitution mutation
\end{abstract}

\section{Introduction}

Mutations of the androgen receptor cause resistance to the action of testosterone and dihydrotestosterone and result in a spectrum of phenotypic abnormalities in $46, X Y$ individuals ranging from women with the syndrome of complete testicular feminization to men with minor degrees of undervirilization. A variety of androgen receptor assays have been utilized to define four broad categories of receptor defects: absence of receptor binding, decreased amount of receptor, qualitative abnormality of the receptor, and receptor-positive androgen resistance (1). This latter designation refers to patients whose fibroblasts demonstrate normal levels of receptor and in whom no qualitative abnormalities of the receptor protein have been detected. Whereas the molecular abnormalities that cause decreased amounts of the androgen receptor or impair receptor function

Received for publication 30 October 1990.

J. Clin. Invest.

(c) The American Society for Clinical Investigation, Inc. $0021-9738 / 91 / 03 / 1123 / 04 \$ 2.00$

Volume 87, March 1991, 1123-1126 in those patients with qualitative and quantitative abnormalities of the androgen receptor are believed to involve the androgen receptor gene, the cause of receptor-positive androgen resistance is unclear. On one hand, receptor-positive androgen resistance could be due to molecular defects in the receptor that impair some step in receptor function distal to ligand binding, such as the binding of the hormone-receptor complex to the nuclear acceptor site, or it could be due to impairment of an even more distal process in the pathway of androgen action. In the present paper we present detailed studies of the androgen receptor gene of a patient with complete testicular feminization associated with an apparently normal androgen receptor. The analysis of the sequence of the androgen receptor gene showed the presence of a single point mutation that converts an adenosine to a guanosine residue at nucleotide 2006 of the androgen receptor cDNA and results in the replacement of arginine 615 with a proline residue. This mutation is located within the second "zinc finger" of the DNA-binding domain, a region believed to be important for the interaction of the androgen receptor protein with androgen-responsive DNA sequences.

\section{Methods}

Cell culture. Fibroblasts were grown from genital skin biopsies in DMEM supplemented with $10 \%$ FCS and $1 \%$ penicillin and streptomycin. The CV-1 cell line was obtained from American Type Culture Collection (Rockville, MD) and grown in DMEM supplemented with $10 \% \mathrm{FCS}$ and $1 \%$ penicillin and streptomycin. DNA was prepared from confluent fibroblast cultures by modification of standard methods (2).

Androgen receptor gene amplification. Genomic DNA from genital skin fibroblasts of patient P321 was amplified as described by the manufacturer using $1 \mu \mathrm{g}$ of genomic DNA and $5 \mathrm{U}$ Taq I polymerase. The sequence and the location of the oligonucleotides used for the amplification has been published elsewhere (3). Amplified bands were cut with Eco RI, subcloned in the sequencing vector MP18 and sequenced by using the dideoxysequencing method (4). The number of glycine repeats contained within the glycine homopolymeric segment could not be ascertained unambiguously, and the number reported (see below) represents a minimum estimate (3). The mutation detected in patient P321 was confirmed in several templates derived from two different amplification reactions.

Site-directed mutagenesis. The mutation detected in patient P321 was incorporated into the oligonucleotides shown below, which span nucleotides 1996 to 2018.

\section{MUT ARG-PROs: CTTGTCGTCTTCGAAATGTTATGA}

\section{MUT ARG-PROas: TCATAACATTTCGGAAGACGACAAG}

These oligonucleotides were used in combination with other oligonucleotides to incorporate the mutation at nucleotide 2006 into the andro- 
gen cDNA sequence. MUT Arg $\rightarrow$ Pro(s) was used together with oligo $710 \mathrm{Xba}(3)$ to amplify a $1-\mu \mathrm{g}$ sample of the normal androgen receptor cDNA. The product of this reaction (reaction I) represents the $3^{\prime}$ terminus of the androgen receptor containing the mutation detected in patient 321 and an artificial Xba I restriction site at the $3^{\prime}$ terminus of the cDNA segment. In a similar fashion, oligonucleotide Arg $\rightarrow$ Pro(as) was used together with oligonucleotide mutH3 (3) to amplify $1 \mu \mathrm{g}$ of the normal androgen receptor cDNA. The product of this reaction (reaction II) contains the mutation detected in patient P321 in a second DNA fragment that extends from the Hind III restriction site, located at nucleotide 1850 of the androgen receptor cDNA (5), up to the $3^{\prime}$ end of oligonucleotide Arg $\rightarrow$ Pro(as). The two segments of DNA derived from these two amplifications (reactions I and II) contain a region of homology of 25 nucleotides. The products of reactions I and II were mixed, annealed, and amplified using oligonucleotides mutH3 and 710 $\mathrm{Xba} \mathrm{I}$. The resulting band was digested with the restriction endonucleases Xba I and Hind III and ligated into the expression plasmid containing the normal human androgen receptor that had been digested previously with these two restriction endonucleases (3). The resulting plasmid, designated CMVmut321, contains the nucleotide substitution detected at residue 2006 in the androgen receptor gene of patient P321. The position of this substitution and the absence of other mutations in the expression plasmid CMVmut 321 were verified by nucleotide sequence analysis.

Cotransfection assay. The functional capacity of the normal and mutant androgen receptors were assayed as described (3). Briefly, 200 ng of the expression plasmid encoding the normal androgen receptor CMV-AR31 or the mutant receptor CMV321 were cotransfected with $10-\mu \mathrm{g}$ aliquots of the receptor plasmid MMTV-CAT into CV1 cells (6). Incubation with steroid were continued for a total of $48 \mathrm{~h}$, with medium changes every $24 \mathrm{~h}$. Chloramphenicol acetyl transferase (CAT) activity was assayed as described (7).

\section{Results}

Identification of the molecular defect in the androgen receptor gene of patient P321. Patient 321 is a woman with complete testicular feminization who presented at age 16 with primary amenorrhea; a sister is similarly affected. As reported previously, monolayer binding assays performed on genital skin fibroblast cultures revealed $28 \mathrm{fmol} / \mathrm{mg}$ of protein of specific dihydrotestosterone binding. These binding sites appear to be functionally normal, as assessed by apparent $K_{\mathrm{d}}$ of ligand binding, thermostability, and migration on sucrose gradients (8). Furthermore, DNA-Sepharose chromatography detected only a single class of labeled receptor molecule that eluted as a sharp peak at $110 \mathrm{mM}$ sodium chloride (data not shown), consistent with the chromatographic behavior of androgen receptor prepared from control fibroblasts (9).

Southern analysis of the structure of the androgen receptor gene in patient P321 indicated that all eight coding exons of the androgen receptor gene are present, and no major deletions or rearrangements were detected (data not shown). To identify any small mutations within the androgen receptor gene, amplification of the coding exons of the androgen receptor gene was performed with the polymerase chain reaction using pairs of oligonucleotides complementary to the intron sequences flanking each exon (3). Agarose gel electrophoresis of the amplified bands indicated that the eight coding exons are normal in size (data not shown). Sequence analysis was performed after subcloning of the amplified bands in the sequencing vector M13 (4). The only difference found within the androgen receptor gene was a single nucleotide substitution $(G \rightarrow C)$ at nucleotide position 2006 (5) which results in the substitution of a proline residue in place of arginine 615 . This mutation is located within exon 3 of the gene, which encodes the second zinc finger of the DNA-binding domain, as shown schematically in Fig. 1.

Binding properties of the mutant androgen receptor containing the arginine to proline substitution at amino acid 615 . The substitution detected in the androgen receptor gene of patient P321 was inserted into a normal androgen receptor CDNA residue using site-directed mutagenesis (3). This expression plasmid, designated CMVmut321, was stably transfected into the human prostate carcinoma cell line PPC-1 (generously provided by Arthur R. Brothman, East Virginia Medical School, Norfolk, VA), which does not express detectable androgen receptor protein or mRNA (McPhaul, M. J., unpublished observations). Table I summarizes the results of assays of specific binding of $\left[{ }^{3} \mathrm{H}\right]$ dihydrotestosterone to the native and mutant androgen receptors expressed in PPC-1 cells. Despite variations in the amount of specific dihydrotestosterone bound to the two receptor proteins, the normal and mutant androgen receptors have a similar apparent $K_{\mathrm{ds}}$.

The androgen receptor containing the mutant amino acid is transcriptionally inactive. The presence of an amino acid substitution in the second zinc finger suggested that the resulting receptor protein might be unable to stimulate transcription of androgen responsive genes. To test this hypothesis CV1 cells were transfected with cDNAs encoding the native and mutant androgen receptors and a reporter plasmid MMTV-CAT (3, 11). In this plasmid the reporter gene is driven by the MMTVLTR, which contains androgen-responsive sequences. The results of such an experiment are shown in Fig. 2. Treatment of the transfected cells with dihydrotestosterone leads to the induction of high levels of CAT activity. By contrast, when the expression plasmid encoding the P321 receptor protein was transfected, androgen stimulation of CAT activity was barely detectable (Fig. 2 and Table II).

Fibroblasts established from patient P321 express normal levels of androgen receptor $m R N A$. Androgen receptor $m R N A$ levels were measured in fibroblasts cultured from patient P321 using a solution hybridization assay $(3,12,13)$ and compared to the levels of RNA from a control strain of fibroblasts. As shown in Fig. 3, fibroblasts from patient P321 express a level of androgen receptor mRNA similar to that in control fibroblasts.
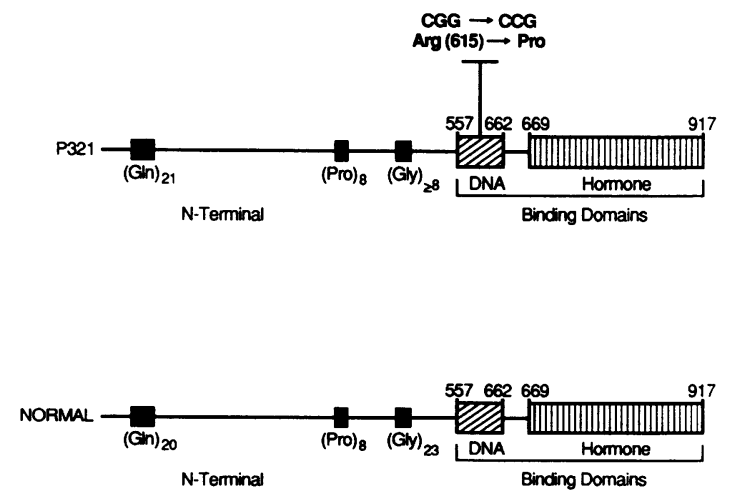

Figure 1. Schematic representation of the normal androgen and the mutant androgen receptor predicted for patient P321. The locations of the hormone- and DNA-binding domains are indicated. The position of the arginine to proline amino acid substitution in the DNA-binding domain is shown. The exact number of residues contained in the glycine homopolymeric segment was not determined and is shown as a minimum estimate (3). 
Table I. Hormone-binding Properties of the Normal and Mutant P321 Androgen Receptor Proteins

\begin{tabular}{lcc}
\hline cDNA & Apparent $K_{\mathrm{d}}$ & $B_{\max }$ \\
\hline & $n M$ & fmol/mg protein \\
Normal & 0.8 & 95 \\
P321 & 0.5 & 35 \\
\end{tabular}

PPC-1 cells were transfected with an expression plasmid encoding the normal or mutant (P-321) androgen receptor and a plasmid encoding a selectable marker (pSV2neo) (10). After selection of G418 resistant colonies, the cells were assayed using a monolayer binding assay to determine the level and affinity of specific $\left[{ }^{3} \mathrm{H}\right] 5 \alpha$-dihydrotestosterone binding.

\section{Discussion}

Androgen resistance encompasses a range of disorders that impede androgen action during embryogenesis and later in life. The phenotypic abnormalities of affected 46,XY individuals range from phenotypic females to minimally undervirilized men. This spectrum of clinical phenotypes is associated with a variety of quantitative and qualitative abnormalities of the androgen receptor. In one category of androgen resistance, termed "receptor-positive" androgen resistance, the androgen receptor appears to be quantitatively and qualitatively normal (1). The apparent absence of defects within the androgen receptor protein has led to the suggestion that such patients represent either defects in the receptor not detected by assays of ligand binding or defects at more distal steps in the pathway of androgen action ("postreceptor").

The subject with complete testicular feminization described in this report (P321) falls within this category, as the androgen receptor in fibroblasts cultured from genital skin bound normal amounts of $\left[{ }^{3} \mathrm{H}\right]$ dihydrotestosterone and did not demonstrate detectable qualitative abnormalities (8). Sequence analysis of the androgen receptor gene detects only a

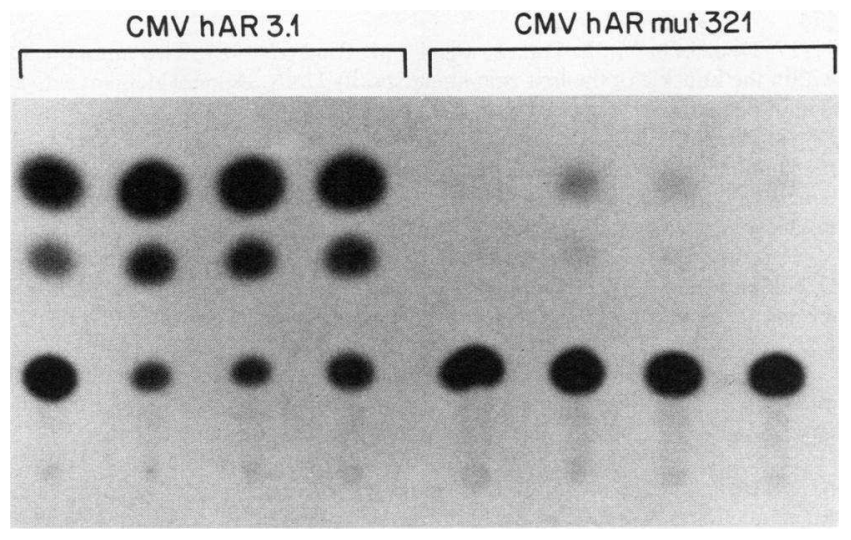

Figure 2. The androgen receptor protein predicted for patient P321 is inactive in transfection assays of receptor function. Dishes of CV1 cells were transfected with aliquots of expression plasmid $(200 \mathrm{ng})$ and the reporter plasmid MMTV-CAT. $12 \mathrm{~h}$ after transfection, the medium was changed to medium containing $2 \mathrm{nM} 5 \alpha$-dihydrotestosterone. After $48 \mathrm{~h}$ of hormone stimulation, the cells were harvested and assayed for chloramphenicol acetyl transferase activity (7).
Table II. Quantitative Comparison of the Functional Capacities of the Normal and Mutant (P321) Androgen Receptors

\begin{tabular}{lcc}
\hline cDNA & $\begin{array}{c}\text { \% Conversion of } \\
{\left[{ }^{14} \mathrm{C}\right] \text { chloramphenicol }}\end{array}$ & \% of control \\
\hline Normal & 81 & 100 \\
P321 & 2.0 & 2.4 \\
\hline
\end{tabular}

Assays were performed by the transfection of CV1 cells with $200 \mathrm{ng}$ of expression plasmid and $10 \mu \mathrm{g}$ of reporter plasmid (MMTV-CAT). After transfection, the cells were incubated with medium containing $2 \mathrm{nM} 5 \alpha$-dihydrotestosterone. The incubation with hormone was continued for a total of $48 \mathrm{~h}$ and was changed after $24 \mathrm{~h}$. Each value represents the average of five separate determinations.

single difference compared to the sequence of the normal androgen receptor: change of the arginine residue at amino acid 615 to a proline residue. This arginine is located within the carboxy terminal portion of the second zinc finger and is conserved among a number of steroid hormone receptors (14).

The function of the two zinc fingers of the DNA binding domain of the glucocorticoid and estrogen receptors have been examined by constructing chimeric estrogen receptors in which either the first or second zinc finger region had been exchanged with that of the glucocorticoid receptor. Both fingers are important for receptor-DNA interaction; the first finger determines the recognition specificity of the hormone responsive

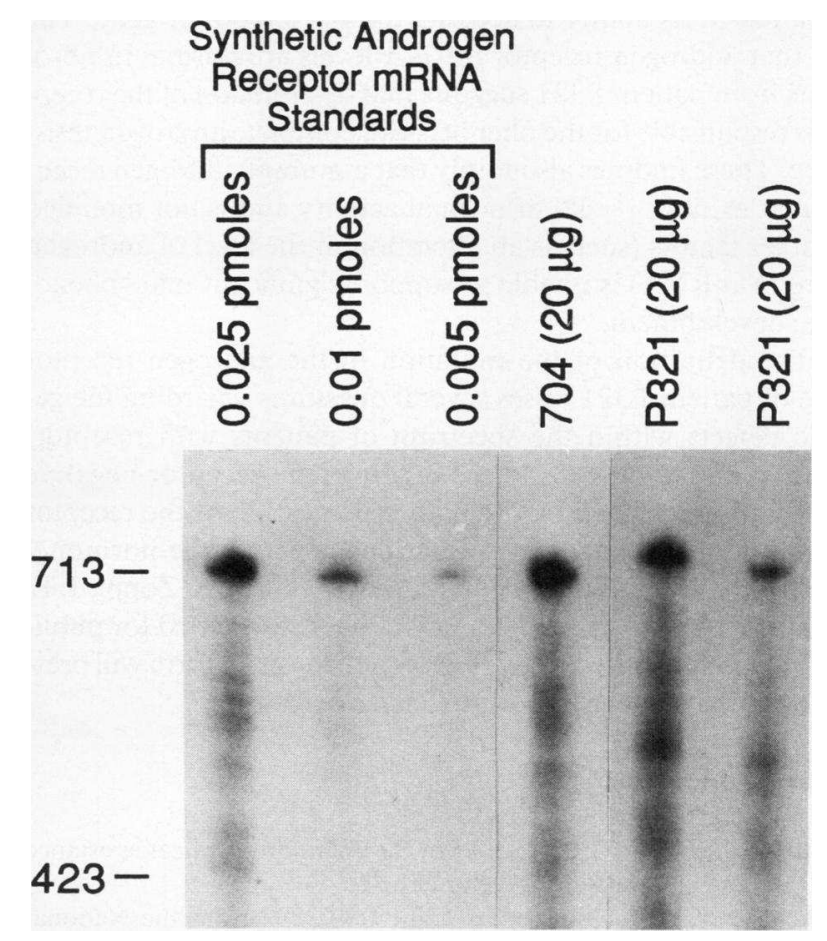

Figure 3. Fibroblasts established from patient P321 express normal levels of androgen receptor mRNA. Aliquots of total RNA were prepared from fibroblasts established from patient P321 and from normal control fibroblasts (704). After hybridization to an RNA probe uniformly labeled with $\left[{ }^{32} \mathrm{P}\right] \mathrm{UTP}$, the mixture was digested with $S_{1}$ nuclease and electrophoresed on a denaturing polyacrylamide gel. 
element, and the second finger, rich in basic amino acids, is important for contacting the DNA phosphate backbone and for stabilizing the protein-DNA binding (15). The region important for specificity has been localized to a group of amino acid residues at the base of the first zinc finger $(16,17)$.

The mutation identified in patient $\mathrm{P} 321$ is interesting in several respects. First, it replaces the arginine residue at amino acid 615 . Although not absolutely conserved, a basic amino acid is present at this position in all steroid receptors, implying that the charge of the amino acid residue at this position may be important to receptor function. Second, this mutation not only removes a basic amino acid but also introduces into this position a residue that is certain to disrupt higher order structure. In fact, this proline residue substitution is positioned in the center of a segment that has an alpha helical conformation in the DNA-binding domain of the glucocorticoid receptor (18). Third, the mutation is similar to mutations in patients with the receptor-positive form of complete vitamin $D$ resistance $(19,20)$. In this regard, it is interesting to note that most mutations identified in the DNA-binding domain of the vitamin $\mathrm{D}$ receptor that cause complete hormone resistance are located in the exon encoding the second zinc finger. Whether this is a statistical aberration or has biological significance will await further study.

The alteration of the structure of the androgen receptor predicted for patient P321 would be expected to impair the interaction of the androgen-receptor complex with androgen responsive elements. In agreement with this expectation, the cotransfection of the expression plasmid encoding the mutant androgen receptor CMV321 and the MMTV-CAT reporter plasmid demonstrate that the P321 mutant receptor is severely impaired in its ability to activate the CAT reporter gene. The fact that androgen receptor mRNA levels are normal in fibroblasts from patient P321 suggests that dysfunction of the receptor is responsible for the phenotype of complete androgen resistance. These findings also imply that a mutant androgen receptor that exhibits $\sim 2 \%$ of normal activity and is not modified by other factors (such as an alteration in the level of androgen receptor $\mathrm{mRNA}$ ) is unable to support significant male phenotypic development.

The definition of the mutation in the androgen receptor gene of patient $\mathrm{P} 321$ raises several questions regarding the genetic defects within the spectrum of patients with receptorpositive androgen resistance. Whereas the receptor-negative form is characterized by premature truncation of the receptor protein $(2,3,21)$ or point mutations affecting the hormonebinding domain (22; Marcelli, M., W. D. Tilley, S. Zoppi, J. E. Griffin, J. D. Wilson, and M. J. McPhaul, submitted for publication), patients affected by the receptor-positive form will present a different spectrum of molecular defects.

\section{Acknowledgments}

We thank Judith A. Gruber and Em Ba Phan for technical assistance and Brenda $\mathrm{H}$. Hennis for secretarial help.

This work was supported by grant DK03892 from the National Institutes of Health, a Basil O'Connor Award from the March of Dimes (\#5-694), the Medical Life and Health Insurance Medical Research Fund, the Welch Foundation (I-1090), and a grant from the Perot Family Foundation. M.J.M. is a Culpeper Medical Scholar.

\section{References}

1. Griffin, J. E., and J. D. Wilson. 1989. The androgen resistance syndromes: $5 \alpha$-reductase deficiency, testicular feminization, and related syndromes. In The Metabolic Basis of Inherited Disease. 6th ed. C. R. Scriver, A. L. Beaudet, W. S. Sly, and D. Valle, editors. McGraw-Hill Book Co., New York. 1919-1944.

2. Marcelli, M., W. D. Tilley, C. M. Wilson, J. D. Wilson, J. E. Griffin, and M. J. McPhaul. 1990. A single nucleotide substitution introduces a premature termination codon into the androgen receptor gene of a patient with receptor negative androgen resistance. J. Clin. Invest. 85:1522-1528.

3. Marcelli, M., W. D. Tilley, J. E. Griffin, J. D. Wilson, and M. J. McPhaul. 1990. Definition of the human androgen receptor gene structure permits identification of mutations that cause androgen resistance: premature termination of the receptor protein at amino acid 588 causes complete androgen resistance. $\mathrm{Mol}$. Endocrinol. 4:1105-1116.

4. Sanger, F., A. R. Carlson, B. G. Barrell, A. J. H. Smith, and B. A. Roe. 1980. Cloning in single-stranded bacteriophage as an aid to rapid DNA sequencing. $J$. Mol. Biol. 143:161-178.

5. Tilley, W. D., M. Marcelli, J. D. Wilson, and M. J. McPhaul. 1989. Characterization and expression of a cDNA encoding the human androgen receptor. Proc. Natl. Acad. Sci. USA. 86:327-331.

6. Graham, F. L., and A. J. Vander Eb. 1973. A new technique for the assay of infectivity of human adenovirus S DNA. Virology. 52:456-467.

7. Gorman, C. M., L. F. Moffat, and B. H. Howard. 1982. Recombinant genomes which express chloramphenicol acetyl transferase in mammalian cells. Mol. Cell. Biol. 2:1044-1051.

8. Griffin, J. E., and J. L. Durrant. 1982. Qualitative receptor defects in families with androgen resistance: failure of stabilization of fibroblast cytosol androgen receptor. J. Clin. Endocrinol. Metab. 55:465-474.

9. Grino, P. B., J. E. Griffin, and J. D. Wilson. 1987. Transformation of the androgen receptor to the deoxyribonucleic acid-binding state: studies in homogenates and intact cells. Endocrinology. 120:1914-1920.

10. Southern, P. J., and P. Berg. 1982. Transformation of mammalian cells to antibiotic resistance with a bacterial gene under control of the SV40 early region promoter. J. Mol. Appl. Genet. 1:327-341.

11. Giguére, V., S. M. Hollenberg, M. G. Rosenfeld, and R. M. Evans. 1986. Functional domains of the human glucocorticoid receptor. Cell 46:645-652.

12. Burke, J. F. 1984. High sensitivity $S_{1}$ mapping with single stranded $\left.{ }^{32} \mathrm{P}\right] \mathrm{DNA}$ probes synthesized from bacteriophage $\mathrm{M} 13 \mathrm{mp}$ templates. Gene (Amst.). 30:63-68.

13. Tilley, W. D., C. M. Wilson, M. Marcelli, and M. J. McPhaul. 1990. Androgen receptor gene expression in human prostate carcinoma cell lines. Cancer Res. 50:5382-5386.

14. Evans, R. M. 1988. The steroid and thyroid hormone receptor superfamily. Science (Wash. DC). 240:889-895.

15. Green, S., V. Kumar, I. Theulaz, W. Wahli, and P. Chambon. 1988. The N-terminal DNA binding "zinc finger" of the oestrogen and glucocorticoid receptors determines target gene specificity. EMBO (Eur. Mol. Biol. Organ.) J. 7:30373044.

16. Mader, S., V. Kumar, H. deVerneuil, and P. Chambon. 1984. Three amino acids of the oestrogen receptor are essential to its ability to distinguish an oestrogen from a glucocorticoid-responsive element. Nature (Lond). 338:271274.

17. Danielsen, M., L. Hunck, and G. M. Ringold. 1989. Two amino acids within the knuckle of the first zinc finger specify DNA response element activation of the glucocorticoid receptor. Cell. 57:1131-1138.

18. Härd, T., E. Kellenback, R. Boelens, B. A. Maler, K. Dahlman, L. P. Freedman, J. Carlstedt-Duke, K. R. Yamamoto, J.-A. Gustafsson, and R. Kaptein. 1990. Solution structure of the glucocorticoid receptor DNA-binding domain. Science (Wash. DC). 249:157-160.

19. Hughes, M. R., P. J. Malloy, D. G. Kieback, R. A. Kesterson, W. J. Pike, D. Feldman, and B. W. O'Malley. 1988. Point mutations in the human vitamin D receptor associated with hypocalcemic rickets. Science (Wash. DC). 242:17021705.

20. Sore, T., S. J. Marx, U. A. Liberman, and J. W. Pike. 1990. A unique point mutation in the human vitamin D receptor. Chromosomal gene confers hereditary resistance to 1,25-dihydroxyvitamin D. Mol. Endocrinol. 4:623-631.

21. Sai, T., S. Seino, C. Chang, M. Trifiro, L. Pinsky, A. Mhatre, M. Kaufman, B. Lambert, J. Trapman, A. O. Brinkman, R. L. Rosenfield, and S. Liao. 1990. An exonic point mutation of the androgen receptor gene in a patient with complete androgen insensitivity. Am. J. Hum. Genet. 46:1095-1 100.

22. Brown, T. R., D. B. Lubahn, E. M. Wilson, D. R. Joseph, F. S. French, and C. J. Migeon. 1988. Deletion of the steroid binding domain of the human androgen receptor in one family with complete androgen insensitivity syndrome: evidence for further genetic heterogeneity in this syndrome. Proc. Natl. Acad. Sci. USA. 85:8151-8155. 